\title{
Demographic and morphological analysis of granulomatous dermatoses
}

\author{
Rajashree K. ${ }^{1, *}$, Hilda Fernandes ${ }^{2}$ \\ ${ }^{1}$ Assistant Professor, Dept. of Pathology, SS Institute of Medical Sciences and Research Center Davangere, Karnataka, \\ ${ }^{2}$ Professor, Dept. of Pathology, Father Muller Medical College, Manglore, Karnataka, India
}

*Corresponding Author:

Email: drrajashree411@gmail.com

\begin{abstract}
Introduction: Granulomatous reaction is chronic inflammatory pattern which is characterized by presence of granulomas. Many of the skin granulomatous conditions produce identical pattern and hence it remains always a diagnostic challenge to pathologist. Arrival at the accurate diagnosis is of great interest so that appropriate treatment can be ensured.

Aim: To study different morphological patterns of granulomatous lesions of the skin along with the etiology and demographic pattern.

Materials and Methods: All the skin biopsies with the histological features of granulomatous disease received in the Pathology Department, Father Muller Medical College for a period of three and half years (Jan 2009 to May 2012) are included in the study. The clinical details and $\mathrm{H}$ and $\mathrm{E}$ sections of all the cases were reviewed.

Results: Of 75 cases of skin biopsies with granulomatous lesions, $65(85 \%)$ were found in males. Out of these, Tuberculoid type of granulomas was seen in 57 cases (76\%), suppurative type in 10 cases (13.4\%), Necrobiotic type in 4(5.3\%) cases and foreign body type in $4(5.3 \%)$ cases. Sixty five cases $(86 \%)$ were infectious granulomatous lesions. Leprosy was amounting to 49 cases $(65 \%)$, followed by tuberculosis and chromoblastomycosis with each of 8 cases. Other causes were foriegn body granuloma, necrobiosis lipoidica and granuloma annulare.

Conclusion: Males are more commonly affected by granulomatous dermatosis. In this study, tuberculoid granulomas were the most common type. The most common cause of granulomatous skin lesion was leprosy. Other common cases were tuberculosis and chromoblastomycosis.
\end{abstract}

Keywords: Granulomatous, Skin, Morphology, Etiology.

\section{Introduction}

Granulomatous reaction is chronic inflammatory pattern characterized by presence of distinctive granulomas. ${ }^{1}$ Granuloma is defined as a focal chronic inflammatory response to various types of tissue injury and is characterised by focal collection of activated macrophages, epithelioid cells and multinucleate giant cells that may or may not be rimmed by lymphocytes and/or show central necrosis. ${ }^{2}$

Granulomatous dermatoses can be due to various causes including organic and inorganic. It is always a diagnostic challenge to dermatopathologists, as similar histologic picture is produced by several causes, and conversely single cause can produce several histotogic picture. ${ }^{3}$

The present study aims at analysing several granulomatous dermatosis received in the department and to classify the same into different categories based on age, gender, etiology and morphology.

\section{Materials and Methods}

The study is retrospective analysis which included all the skin biopsies received in the Department of Pathology, Father Muller Medical College Hospital, Mangalore over a period of three and a half years (Jan 2009- May 2012).

The cases with histopathotogical diagnosis of granulomatous diseases were retrieved. Hematoxylin and eosin stained sections were reviewed. Special stains (Periodic Schiff, Acid fast stain, Fite stain and Gomori
Methamine silver) were performed where ever needed. The clinical details and diagnosis were also noted from the histopathology records. The granulomas were subclassified into Sarcoidal, tuberculoid, necrobiotic, suppurative, foreign body and miscellaneous granulomas. ${ }^{1}$

\section{Results}

A total of 75 cases of ganulomatous dermatoses were retrieved. Out of which $65(85 \%)$ were males and $10(15 \%)$ were females with male to female ratio 2.5:1. Ages ranged from 2-85 yrs with mean of 40.3 yrs. Maximum number of cases were concentrated in the $3^{\text {rd }}$ followed by $4^{\text {th }}$ decade. Majority of the cases $(85 \%)$ were categorized into infectious origin, where as rest of the cases $(15 \%)$ as non infectious granulomatous lesions.

Out of 75 cases, 57 (76\%) showed tuberculoid granulomas (Fig. 1.), 10(13.4\%) had suppurative type, $4(5.3 \%)$ cases, each of which had necrobiotic and foreign body type.

Leprosy (Fig. 2) constituted majority of cases amounting to 45 (65.3\%). Tuberculosis and chromoblastomycosis constituted second largest group with 8 cases each $(10.6 \%)$. Other rare conditions are as shown in table 1 . 
Table1: Etiological categorisation of granulomatous dermatosis

\begin{tabular}{|l|c|c|c|}
\hline S. No & Lesions & No. of cases & Percentage \\
\hline 1 & Leprosy & 49 & 65.3 \\
\hline 2 & Tuberculosis & 8 & 10.7 \\
\hline 3 & Chromoblastomycosis & 8 & 10.7 \\
\hline 4 & Granuloma annulare & 3 & 4 \\
\hline 5 & Actinomycosis & 2 & 2.7 \\
\hline 6 & Foreign body reaction & 4 & 5.3 \\
\hline 7 & Necrobiosis lipiodica & 1 & 1.3 \\
\hline
\end{tabular}

The most common cause was leprosy constituting 49 cases $(65.3 \%)$. It was more common among the males with male to female ratio of $3: 1$. On further sub classification, borderline tuberculoid constituted majority i.e 34 cases $(69.38 \%)$ followed by tuberculoid type.

The second most common cause was tuberculosis with 8 cases. Six cases were seen in males with male to female ratio of 3:1. On further sub classification, there were 5cases of Lupius vulgaris (LV)and 3 cases of Tuberculosis verucosa cutis( TVBC)(Fig. 3). Ziehl Neelsen stain for AFB was positive in three cases out of eight cases $(37.5 \%)$.

Chromoblastomycosis (Fig. 4) was noted in frequency similar to tuberculosis. Males dominated with male to female ratio of $7: 1$. Among 8 cases, 6 cases were elderly male. Copper penny bodies which represent pigmented spores were seen in 6 out of 8 cases.

Another fungal organism noted was actinomycosis (Fig. 5). It is more common in elderly male. Both the cases were male in $4^{\text {th }}$ decade.

Granuloma Annulare constituted 3 cases. Two out of 3 were males. All cases were in $5^{\text {th }}$ decade.

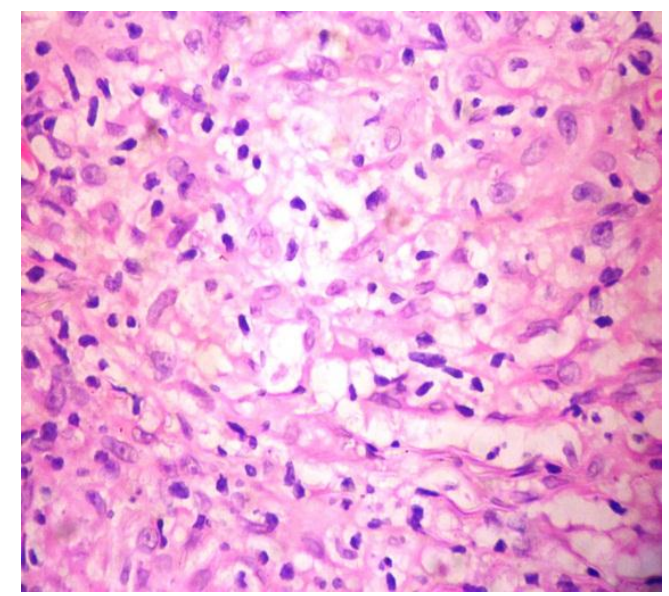

Fig 1: Tuberculoid Granuloma composed of clusters of epithelioid cells admixed with lymphocytes.

(H\&E, $x$ 100)

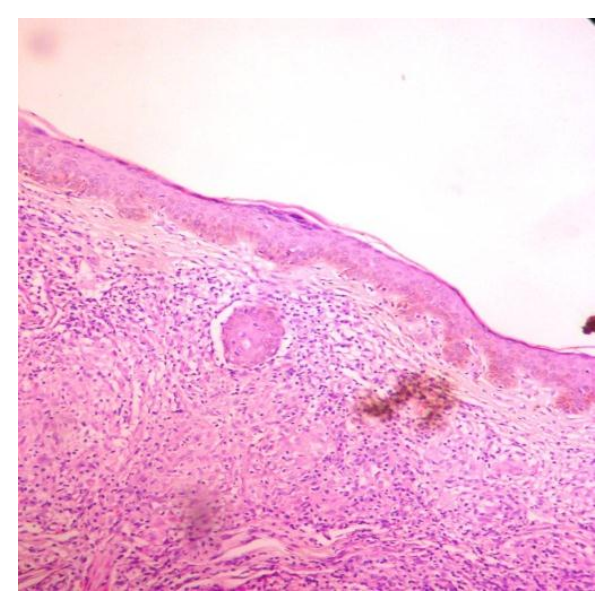

Fig. 2: Borderline tuberculoid leprosy with numerous granulomas in the dermis $(\mathrm{H \& E}, \mathrm{x} 100)$

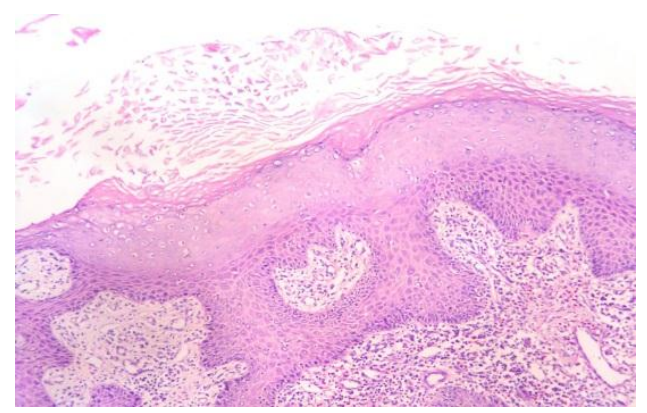

Fig. 3: Tuberculosis verrucosa cutis showing epidermal hyperplasia and few illdefined granulomas in dermis (H\&E, $x$ 100)

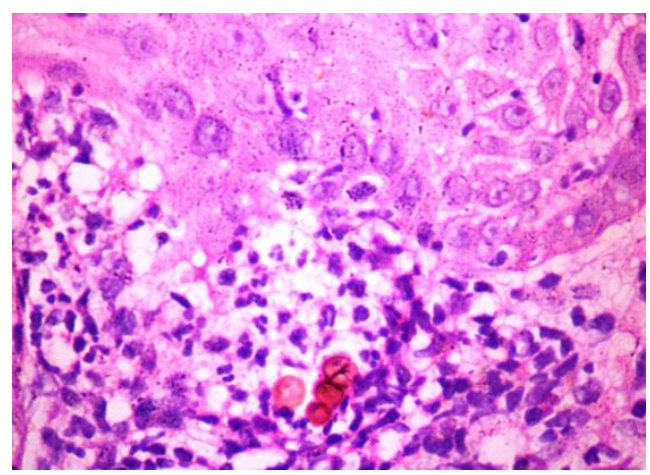

Fig. 4: Chromoblastomycosis pigmented spores resembling copper pennies. (H\&E x100) 


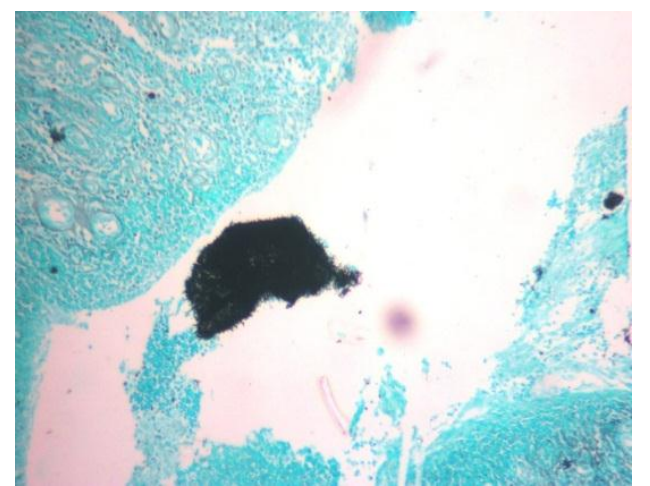

Fig. 5: Actinomycosis surrounded by granulomas (Gommori methamine silver stain, x100)

\section{Discussion}

Granulomatous inflammation was recognized as a distinct entity in the early nineteenth century. It is type IV hypersensitivity reaction to offending antigens.
Arrival at a proper diagnosis is mandatory so that appropriate treatment can be administered. Histopathology remains a time tested tool for establishing diagnosis like in many other diseases pertaining to various organ systems of the body. ${ }^{4}$

The present study showed male predominance of granulomatous lesions of skin which was in accordance with study by Bal A et $\mathrm{al}^{3}$ and Dhar. ${ }^{4}$

Age ranged from 2- 85 yrs with mean age of 40.3 yrs that is concordant to $\mathrm{Bal}$ et at. ${ }^{3}$

The etiology for granulomatous dermatoses can be classified into infectious and non infectious. In our study. Infectious granulomatous lesions predominated which was concordant with other study. ${ }^{6}$

The most common granulomatous pattern in our study was tuberculoid followed by suppurative which is comparable with other studies. (Table 2)

Table 2: Comparision of morphology of granulomatous dermatoses with different other studies

\begin{tabular}{|c|c|c|c|c|c|c|}
\hline S. No & Other studies & Tuberculoid & Suppurative & Necrobiotic & Foreign body type & Miscellaneous \\
\hline 1 & Dhar and Dhar et $\mathrm{al}^{4}$ & 77.3 & 9 & - & - & - \\
\hline 2 & Bal et $\mathrm{al}^{3}$ & 87.7 & 2.9 & 2.6 & 1.7 & 2.4 \\
\hline 3 & Zafar et $\mathrm{al}^{5}$ & 92.7 & 3.3 & 0.8 & 3.3 & - \\
\hline 4 & Gautham et al $^{6}$ & 68.9 & 2.8 & 0.8 & 3.3 & 3.7 \\
\hline 5 & Present study & 76 & 13.4 & 5.3 & 5.3 & - \\
\hline
\end{tabular}

Leprosy was the commonest granulomatous lesion of the skin. This was concordant with study by Gautham et at, ${ }^{6}$ but discordant with Zafar et $\mathrm{al}^{5}$ and Quershi et $\mathrm{al}^{7}$ who found tuberculosis to be most common cause.

The occurance of different granulomatous lesions of skin depends on cause present atparticular geographical location.

Skin lesions in leprosy were common among the males. The results were comparable with Gautham who found male predominance with male to female ratio 2.8:1. ${ }^{6}$ Majority i.e. thirty four cases were borderline tuberculoid. This finding was concordant with Gautham et al. ${ }^{6}$

Among the 8 cases of tuberculosis, males predominated, which was similar to Gautham et al, ${ }^{6}$ Senguptha et at ${ }^{8}$ and Sehgal et al. ${ }^{9}$ The age ranged from 16-25 yrs. On further classification, there were 5 cases each of Lupus vutgaris and 3 cases of tuberculosis verrucosa cutis which was consistent with Zafar et al. ${ }^{5}$

Diagnosis of cutaneous tuberculosis requires evidence of the presence of the tubercle bacilli either in smear or tissue section as demonstarted by Ziehl Neelson stain. Ziehl Neelsen stain for AFB was positive in three cases out of eight cases $(37.5 \%)$ which was concordant with Zafar et at. ${ }^{5}$ All the reported special stain positive three cases were TBVC. Among eight cases of chromoblastomycosis, males dominated which was in concordant with study by Gautham et al. ${ }^{6}$ All cases showed pseudoepitheliomatous hyperplasia, microabcesses, epithiloid cells and multinucleate giant cells. Six out of eight cases showed dark brown copper penny bodies. In cases where fungal organisms are not identified, but a high index of suspicion is present, a fungal culture is always confirmatory. ${ }^{6}$

Granuloma annulare accounted for 3 cases which is similar to study by Gautham et al. ${ }^{6}$ It is uncommon disease which resolve without any clinical sequel. Its frequency in general population is unknown. Two out of three cases were male and both were seen in $5^{\text {th }}$ decade.

\section{Conclusion}

Our study shows granulomatous lesions of skin are more common in males, with wide age range. Tuberculoid type is the most common type. Leprosy is the leading cause followed by tuberculosis and fungal infections. Other rare causes are granuloma annulare, necrobiosislipiodica. There is overlap in histopathologic picture of different granulomatous reactions. Thus morphology alone is not very specific. Usage of special stains will help to arrive at definitive diagnosis.

\section{References}

1. Weedon D. The granulomatous reaction pattern. In: Weedon D (ed). Skin Pathology, 2nd ed. Philadelphia: Churchill Livingstone;2002.193222.

2. Hirsh BC and Johnson WC. Concepts ofgranutomatous inflammation. Int J Dcrmatol 1984;23:90-9. 
3. Bal A, Mohan H, Dhami GP. Infectious granulomatous dermatitis: A clinicopathological study. Indian J Dermatol 2006;51(6):217-20.

4. Dhar S, Dhar S. Histopathological features of granulomatous skin diseases: an analysis of 22 skin biopsies. Indian J Dermatol. 2002;47:88-90.

5. Zafar MNU, Sadiq S, Mcnon MA. Morphological study of different granulomatous lesions of skin. J Pak Assoc Dermatol 2008;18;21-8.

6. Gautham K, Pai $\mathrm{R}^{2}$, Bhat $\mathrm{S}^{2}$. Granulomatous lesions of the skin. J. Pathology Nepal 2011;1;81-6.

7. Quershi R, Shiekh R, Haque A. chronic granulomatous inflammatory disorders of skin at a tertiary care hospital in Islamabad. International $J$ of pathology. 2004:2(1):31-34.
8. Sengupta LK, Talukdar G, Sharma A. Cell-mediated immunity in cutancous tuberculosis. Indian J Med Res 1981;73:746-50.

9. Sehgal VN, Srivastava G, Khurana VK. An appraisal of epidemiologic, clinical, bacteriologic, histopathologic, and immunologic parameters in cutaneous tuberculosis. Int J Dermatol. 1987;26:521-6. 